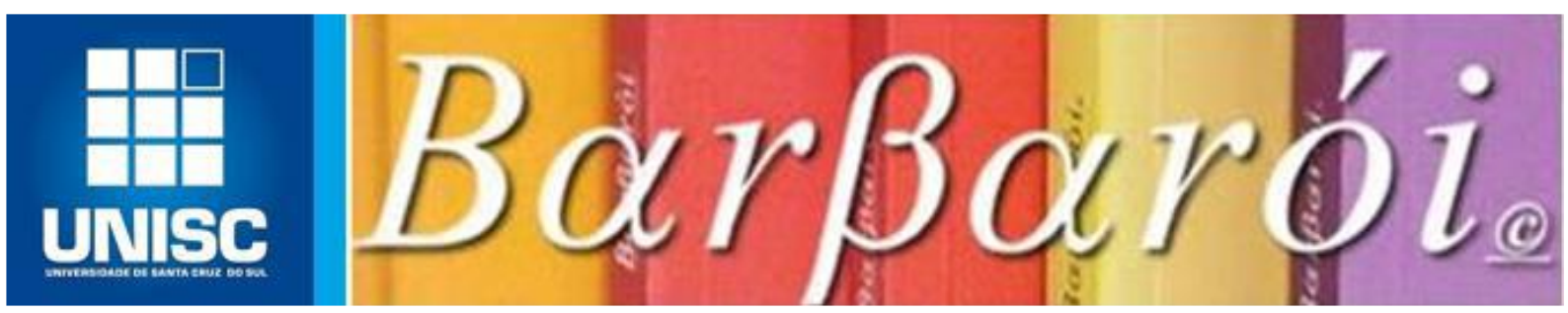

\title{
ENTRE INCERTEZAS E LIMITAÇÕES: UMA ANÁLISE SOBRE O RETORNO AO TRABALHO PÓS TRANSPLANTE RENAL
}

\author{
DOI: http://dx.doi.org/10.17058/barbaroi.v0i0.14805 \\ Jéssica Rayane dos Santos \\ Universidade Federal do Ceará-UFC-Brasil \\ Maria das Graças Fonseca Rocha \\ Hospital Universitário Walter Cantídio - HUWC-UFC - Brasil \\ Maria de Fátima Sousa Lima de Carvalho \\ Hospital Universitário Walter Cantídio - HUWC-UFC - Brasil
}

\section{Resumo}

O presente estudo tem como objetivo geral analisar o retorno ao trabalho dos transplantados renais acompanhados no Hospital Universitário Walter Cantídio (HUWC). A pesquisa traz como objetivos específicos: 1) identificar os fatores que influenciam no processo de retorno ao trabalho; 2) identificar o índice de reinserção ao trabalho por transplantados renais atendidos no HUWC no período de junho/2018 a dezembro/2018. Trata-se de pesquisa qualitativa que conforme Minayo (2011), trabalha um universo de significados, motivações, aspirações, crenças, valores e atitudes, o que corresponde a um espaço mais profundo das relações dos processos e dos fenômenos que não podem ser traduzidos em números e indicadores quantitativos. Na estruturação metodológica do estudo realizamos pesquisa bibliográfica, pesquisa documental e pesquisa de campo, utilizando, para a análise dos dados, a análise de conteúdo, considerada como o tipo de metodologia particularmente utilizada para estudar material do tipo qualitativo possibilitando, assim, um estudo crítico dos dados coletados, das representações sociais dos sujeitos entrevistados, estabelecendo, por sua vez, um diálogo com o fenômeno estudado. Compreendemos que a submissão ao transplante renal traz impactos positivos para os que aderem ao tratamento, sobretudo em relação à melhoria da qualidade de vida, e na autonomia das atividades da vida diária. Não obstante, em relação à realização de atividades laborais o que se observa é que de um modo geral é difícil o retorno ao trabalho, mantendo-se a dependência de benefícios da seguridade social, e os que conseguem algum retorno ao trabalho, o conseguem de forma gradativa, informal e sem suporte de outras políticas sociais, principalmente as relacionadas a reabilitação profissional.

Palavras-chave: Retorno ao Trabalho. Sistema Único de Saúde.Transplante Renal.

\section{Introdução}

A evolução científica-tecnológica trouxe o conceito de Determinantes Sociais da Saúde (DSS) como relevantes para a definição de metodologias dos estudos epidemiológicos e no 
próprio conceito de saúde, uma vez que, conforme Buss e Pellegrini Filho (2007), as diversas definições de DSS expressam o conceito de que as condições de vida e trabalho dos indivíduos e de grupos de uma população estão relacionadas com a sua situação de saúde. A Organização Mundial de Saúde (OMS) define DSS como as condições sociais em que as pessoas vivem e trabalham. No Brasil, a Comissão Nacional Sobre os Determinantes Sociais (CNDSS) adotam um conceito mais ampliado de DSS, incluindo os fatores sociais, econômicos, culturais, étnicos/raciais, psicológicos e comportamentais que influenciam a ocorrência de problemas de saúde e seus fatores de risco na população (BUSS e PELLEGRINI FILHO, 2007).

O Sistema Único de Saúde no Brasil - SUS, constituido por meio da lei 8.080/90, em seu art. $3^{\circ}$. traz a definição de fatores determinantes e condicionantes de saúde, dentre outros: a alimentação, a moradia, o saneamento básico, o meio ambiente, o trabalho, a renda, a educação, o transporte, o lazer e o acesso a bens e serviços essenciais, (BRASIL, 1990). Sendo esses fatores de ordem social, compreendemos que a política de saúde reafirma a importância dos diversos aspectos sociais que interferem no processo de saúde-doença de sujeitos ou grupos sociais, dos quais nos chama atenção o fator trabalho, sendo este proporcionador direto de outros fatores como a renda, a alimentação, a moradia, o lazer, que são relevantes no processo de manutenção e/ou recuperação da saúde. Esse processo também está presente no texto do SUS, que apresenta, dentre seus objetivos, a promoção, proteção e recuperação da saúde.

O interesse no tema surgiu a partir da experiência como Assistente Social Residente no ambulatório de transplante renal do Hospital Universitário Walter Cantídio, da Universidade Federal do Ceará (HUWC/UFC), onde foi possível compreender melhor o exercício profissional do(a) assistente social no campo da saúde, quanto à formulação e planejamento do trabalho, verificando a atuação profissional a partir da interlocução com as diversas categorias de profissionais de saúde, em âmbito interno, uma vez que, de modo geral, os ambulatório de transplantes do HUWC são compostos por uma equipe multiprofissional; e no âmbito externo, com as diversas políticas públicas setoriais, no processo de intervenção social junto aos pacientes pré e pós transplante.

No pré-transplante, a principal atividade realizada pelo Assistente Social é a entrevista social, onde são coletadas informações de extrema relevância para o acompanhamento social do paciente candidato ao transplante. A Entrevista Social permite o conhecimento das condições socioeconômicas e do contexto social do paciente, a identificação das demandas sociais que possam interferir no tratamento indicado e as possibilidades de intervenção profissional no atendimento dessas demandas. Após a realização do transplante, segue-se com as ações direcionadas a orientar os pacientes em relação aos direitos sociais, tanto na política Barbarói, Santa Cruz do Sul, n. 56, p.<189-207>, jan./jun. 2020 
de saúde, quanto nas demais políticas setoriais.

$\mathrm{Na}$ interlocução com essas políticas públicas, destacam-se as políticas relacionadas ao campo do trabalho, que vem apresentando instabilidade e modificações, sendo uma preocupação geral dos cidadãos brasileiros, sobretudo aqueles acometidos com uma doença grave que requer tratamentos de alta complexidade, como o transplante renal. No atendimento e acompanhamento social a esses pacientes, a demanda mais frequente é em relação ao campo de direitos trabalhistas e sociais.

Assim, verificamos a importância de se aprofundar o conhecimento acerca dos problemas causados pela nova ordem do capital sobre o trabalho, que tem como consequência modificações profundas na forma como os indivíduos se relacionam com o trabalho, e sobre os impactos causados por esses problemas, que interferem direta ou indiretamente na sua saúde e bem- estar. Desse modo, surgiu a necessidade de compreender o trabalho e sua relação com o processo de saúde-doença tomando como particularidade a realidade vivenciada pelos transplantados renais, que nos levou aos seguintes questionamentos: É possível ao transplantado renal retomar suas atividades de trabalho? De que forma isso ocorre?

As respostas para esses questionamentos viriam mediante um olhar mais acurado das questões que envolvem o trabalho dentro de uma perspectiva de adoecimento, ou seja, o retorno ao trabalho depois de um diagnóstico de doença que requeira longo período de afastamento das atividades laborativas. Assim surgiu o interesse em analisar o retorno ao trabalho após a realização de transplante renal, tendo como sujeitos os transplantados renais acompanhados no serviço de transplante renal do Hospital Universitário Walter Cantídio (HUWC), da Universidade Federal do Ceará (UFC), propondo uma reflexão acerca da relação entre a qualidade de vida do transplantado renal e o retorno ao trabalho, trazendo ao centro da discussão o trabalho como determinante de saúde e direito social, bem como o significado da categoria trabalho no contexto social de pessoas submetidas a transplante renal.

A pesquisa tem como objetivos específicos: 1) identificar os fatores que influenciam no processo de retorno ao trabalho; 2) identificar o índice de reinserção ao trabalho por transplantados renais atendidos no HUWC no período de junho/2018 a dezembro/2018.

Justifica-se a realização da pesquisa no atual cenário político, social e econômico, considerando, principalmente, as transformações ocorridas no mundo do trabalho que incidem na garantia de direitos sociais e trabalhistas. Além disso a investigação da situação ocupacional pós- transplante renal é pouco utilizada nas verificações das iniquidades em saúde, o que torna o tema atual e relevante para o campo acadêmico e profissional, sobretudo na área social que propõe uma intervenção a partir de um estudo crítico-reflexivo da realidade. 


\section{Método}

Compreendemos que a etapa mais complexa de uma pesquisa é justamente aquela que definirá o seu caráter científico, ou seja, a metodologia adotada na identificação, coleta e análise dos dados e/ou fatos pesquisados, sendo necessária uma abordagem que confirme as intenções do pesquisador no estudo em questão. A nossa intenção é de uma análise de significados, embora apresente alguns dados quantitativos, encontrando, assim, amparo na abordagem qualitativa, que, conforme Minayo (2011), trabalha um universo de significados, motivações, aspirações, crenças, valores e atitudes, o que corresponde a um espaço mais profundo das relações dos processos e dos fenômenos que não podem ser traduzidos em números e indicadores quantitativos.

$\mathrm{Na}$ estruturação metodológica do estudo realizamos pesquisa bibliográfica e pesquisa de campo. A pesquisa bibliográfica se realiza no sentido de fornecer elementos teóricos acerca do tema, e análise das categorias centrais da pesquisa. Conforme Gil (1999, p. 50), "a principal vantagem dessa pesquisa reside no fato de permitir ao investigador a cobertura de uma gama de fenômenos muito mais ampla do que aquela que poderia pesquisar diretamente". Incluímos aqui a pesquisa documental na qual procedemos à análise das entrevistas sociais realizadas pela assistente social que atua no ambulatório de transplante renal.

A pesquisa de campo constitui-se do concreto, do real vivido pelo sujeito, o ponto chave do estudo; "em síntese, é fruto de um momento relacional e prático: as inquietações que nos levam ao desenvolvimento de uma pesquisa nascem no universo do cotidiano" (MINAYO, 2011, p.64). O lócus da pesquisa de campo foi o serviço de transplante renal do Hospital Universitário Walter Cantídio (HUWC) da Universidade Federal do Ceará (UFC), utilizandose a técnica da entrevista semiestruturada, relacionada por Minayo (2011) como modalidade que possibilita a formulação de um roteiro previamente estabelecido, podendo ser facilmente alterado no decorrer da entrevista. É um momento em que pesquisador e pesquisado interagem, versando sobre o tema estudado, assim definido por Gil (1999):

\footnotetext{
Pode-se definir entrevista como a técnica em que o investigador se apresenta frente ao investigado e lhe formula perguntas, com o objetivo de obtenção dos dados que interessam à investigação. A entrevista é, portanto, uma forma de interação social. Mais especificamente, é uma forma de diálogo assimétrico, em que uma das partes busca coletar dados e a outra se apresenta como fonte de informação. (GIL, 1999, p.109)
}

$\mathrm{Na}$ análise dos dados coletados utilizamos a Análise de Conteúdo, considerada como o tipo de metodologia particularmente utilizada para estudar material do tipo qualitativo, consistindo num conjunto de técnicas de análise das comunicações, visando, através de procedimentos sistemáticos e objetivos, obter descrição do conteúdo das mensagens e Barbarói, Santa Cruz do Sul, n. 56, p.<189-207>,jan./jun. 2020 
indicadores, quantitativos ou não (GIL,1999; BARDIN 1979), possibilitando, assim, um estudo crítico dos dados coletados, das representações sociais dos sujeitos entrevistados, estabelecendo, por sua vez, um diálogo com o fenômeno estudado. Bardin (2010) afirma que a Análise de Conteúdo se organiza a partir das fases de pré análise, exploração do material e o tratamento dos resultados e interpretação.

O Universo da pesquisa foi composto por pacientes que foram submetidos ao transplante renal, atendidos pelo Serviço Social no ambulatório, no período de junho de 2018 a dezembro de 2018, sendo retirada preliminarmente do Sistema Master1 uma amostra de 30 pacientes a partir dos seguintes critérios de inclusão:1) idade a partir de 18 anos; 2) transplantados há menos de 3 anos. A análise foi feita por amostragem, chegando ao quantitativo 10 de pacientes que tiveram consultas de retorno agendadas para setembro até novembro/2019, no ambulatório do transplante renal, sendo, na oportunidade, realizada a coleta de dados da pesquisa.

Esse estudo segue as orientações da Resolução no 466/2012 da Comissão Nacional de Ética em Pesquisa (CONEP), vinculada ao Conselho Nacional de Saúde (CNS) do Ministério da Saúde. A pesquisa foi submetida à Plataforma Brasil e aprovada pelo Comitê de Ética em Pesquisa (CEP) do Hospital Universitário Walter Cantídio sob o número do parecer: 3.653.202, os dados foram coletados após aprovação da proposta pelo CEP.

Os participantes em potencial foram contatados previamente, por meio de ligação telefônica, sendo-lhes apresentada a proposta da pesquisa, e, em caso afirmativo de participação, agendado dia e horário para realização das entrevistas que ocorreram de forma presencial na Sala do Serviço Social, do ambulatório do transplante renal do HUWC. Os sujeitos que participaram da pesquisa assinaram o termo de consentimento livre e esclarecido, confirmadas a participação de 10 pacientes, sendo, no entanto, concluídas 9 entrevistas, pela ausência de 01 participante nessa etapa.

\section{Considerações sobre o trabalho e o transplante renal}

O conceito de trabalho, na análise Marxiana, conforme Mendes e Wush (2015), está relacionado à capacidade que o homem tem de transformar a natureza, empregando sua força para produzir meios para sua sobrevivência e "ao empregar suas capacidades o homem modifica a natureza externa a ele, mas, ao mesmo tempo, modifica a sua própria natureza, pois se encontra interligado à natureza enquanto uma força natural dotada de capacidade física e mental

\footnotetext{
${ }^{1}$ O Sistema Master refere-se ao sistema de integrado de administração hospitalar e controle clínico do complexo hospitalar da Universidade Federal do Ceará (UFC)
} 
que atua de maneira orientada com um propósito"(MENDES;WUSH, 2015, p. 293). Compreendemos ser esse o sentido que Antunes (1995) emprega à categoria trabalho, pois refere que o trabalho é considerado "modelo", "fenômeno originário", protoforma social, pois o fato de que no trabalho se realiza uma posição teleológica, o configura como uma experiência elementar da vida cotidiana, tornando -o um componente inseparável dos seres sociais.

O aprofundamento da análise do trabalho como elemento fundamental para a vida, torna mais próxima a sua relação com a conceituação de saúde, sendo importante salientar que "na medida em que se considera indissociável a relação entre vida e trabalho, fica evidente a relação entre trabalho e saúde, ou seja, o trabalho tem a potencialidade de ser fonte de saúde bem como de adoecimento" (MENDES; WUSH, 2015, p.299). Nessa perspectiva, de acordo com a OMS (2011) o trabalho passou a fazer parte do rol dos determinantes sociais de saúde, que promovem uma ampliação do conceito de saúde considerando as condições sociais em que as pessoas vivem e trabalham, incluindo-se as condições de ambiente de trabalho, o acesso a serviços de saúde, educação e demais políticas sociais. Assim, a saúde passou a ser definida como o completo bem-estar físico, mental e social do indivíduo.

Contrapondo-se ao conceito ampliado de saúde, surgem as doenças crônicas ou agudas, as quais requerem do poder público, políticas eficazes de enfrentamento das mesmas, no sentido de que prevaleça a saúde como dominante no contexto de vida da população. No cenário brasileiro situam-se as doenças crônicas não transmissíveis como mais prevalentes. Dados do Ministério da Saúde, em 2014, apontam um percentual de 57,4 milhões de brasileiros com pelo menos uma doença crônica, sendo um dos mais graves problemas de saúde pública no Brasil a Insuficiência Renal Crônica (IRC), caracterizada pela perda progressiva e permanente da função dos rins, inserida nos atendimentos de alta complexidade do Sistema Único de Saúde.

Dentre os tipos de terapia nos tratamentos de IRC o transplante renal tem sido a opção mais eficaz, em que o paciente recebe um rim sadio de um doador vivo ou falecido, sem, no entanto, significar o fim do tratamento, mantendo-se o acompanhamento médico periódico.

No Ceará, segundo dados do ambulatório de transplante renal do HUWC/UFC, os estudos sobre transplante tiveram início em 1975, quando se inaugurou o Centro de Pesquisa em Doenças Hepato-Renais do Ceará (Cephrece), com o objetivo de apoiar o ensino e a experimentação clínico-cirúrgica, visando ao aperfeiçoamento de técnicas e conhecimentos que viabilizam os transplantes de órgãos. No ano de 1977, foi realizado o primeiro Transplante Renal no HUWC, sendo a primeira intervenção desse tipo realizada no Norte-Nordeste do Brasil.

De acordo com dados da Secretaria Estadual de Saúde (SESA), no ano de 2018, o estado Barbarói, Santa Cruz do Sul, n. 56, p.<189-207>,jan./jun. 2020 
do Ceará alcançou o segundo melhor resultado, totalizando 1.536 transplantes de órgãos, foram 17 transplantes a mais que no ano anterior. Com relação ao transplante renal, destaca-se que entre janeiro e setembro de 2019 foram realizados 194 procedimentos no Estado, conforme dados da Associação Brasileira de Transplantes de Órgãos (ABTO). Se, por um lado, comemora-se o sucesso das intervenções realizadas, por outro, verifica-se ser este um fator preocupante, já que revela o volume de adoecimento da população, sem mencionar a quantidade de pessoas que aguardam em fila de transplantes.

Conforme estabelece a ABTO (2019), o tratamento pós transplante renal requer uma série de recomendações, tais como: uso contínuo da medicação imunossupressora, orientações dietéticas e atividade física contínua de acordo com as orientações da equipe multiprofissional. Mesmo com a continuidade do tratamento, é possível que o paciente retome de forma gradativa à sua rotina habitual de convívio familiar e social, sendo uma das preocupações mais frequentes a sua condição de saúde para retorno das atividades laborais, uma vez que a situação financeira é motivo de grande preocupação.

Assim, compreendemos que as questões que envolvem o fator trabalho podem interferir de forma significativa na eficácia do tratamento, uma vez que tem inúmeros significados para a vida do transplantado, pois envolve as necessidades materiais e imateriais indispensáveis à sua existência dentro da sociedade, sendo relevante a possibilidade de retorno às atividades laborais. No entanto, esse retorno não pode ocorrer por vontade própria, mas somente após a liberação do profissional que acompanha o tratamento. "O médico indicará ao paciente quando poderá retornar ao trabalho e às outras atividades cotidianas. Esta integração será gradativa. tempo de licença do trabalho poderá ser longo, mas de maneira geral todos os transplantados podem voltar a trabalhar" (ABTO, 2019, p.19).

No Brasil não existe uma legislação específica referente a garantia de direitos da pessoa transplantada, sobretudo quando se refere a aspectos trabalhistas; em tese, o que existem são propostas como a que tramita na câmara em forma de um projeto de lei $\mathrm{n}^{\mathrm{o}}$ 155/2015 que prevê aos pacientes renais crônicos os mesmos direitos garantidos às pessoas com deficiência, sendo necessária a comprovação da paralisia total da função dos rins. Os pacientes que se submeterem ao transplante renal, contudo, terão sua situação reavaliada.

Barata (2009) destaca que o contexto social determina a cada indivíduo sua posição e esta, por sua vez, determina as oportunidades de saúde segundo exposições a condições nocivas ou saudáveis e segundo situações distintas de vulnerabilidade. Consideramos o sujeito transplantado renal vivendo em situação de vulnerabilidade, tendo as condições de vida e de renda como agravantes e/ou determinantes na qualidade e sucesso do tratamento. 


\section{A pesquisa: apresentação e análise de dados}

Sabemos que os problemas de saúde de uma população estão intimamente relacionados com o nível de desenvolvimento socioeconômico de uma determinada região. Dados da Pesquisa Nacional por Amostra de Domicilio (PNAD) realizada em 2015 mostram que as regiões norte e nordeste do Brasil, apresentam os maiores índices de desigualdades sociais, de analfabetismo e de condições precárias de trabalho. Não por acaso o serviço de transplante renal do HUWC recebe na maioria dos atendimentos, pessoas provenientes dessas regiões, que também apresentam precariedade nos serviços de atenção básica à saúde.

Com base nas entrevistas sociais analisadas na pesquisa bibliográfica, e nos discursos dos participantes, foram construídas duas categorias de análise: 1) o modo de vida dos transplantados renais do HUWC; 2) a situação do transplantado no mercado de trabalho.

\section{1. O modo de vida dos transplantados renais do HUWC}

Compreendemos como modo de vida o contexto em que o sujeito se insere, tais como as condições sociais e econômicas, trabalho e renda, a situação familiar, bem como a sua fala em relação ao processo da doença e acesso ao tratamento de saúde, as suas impressões positivas ou negativas a respeito do tratamento e da qualidade de vida. Assim, trazemos nesse item a análise dos dados da pesquisa, sendo os participantes referenciados com uma numeração de 1 a 9, conforme a realização das entrevistas, e, no sentido de se preservar a identidade dos mesmos, mantendo-se o comprometimento ético da pesquisa

Os sujeitos da pesquisa apresentam as seguintes características: idade entre 24 e 61 anos, sendo 2 do sexo feminino e 7 do sexo masculino. Em relação ao estado civil 4 entrevistados são solteiros, 4 casados e 1 divorciado. Quanto à origem, foram contemplados pacientes

procedentes das regiões norte e nordeste, sendo 4 participantes originários da Paraíba; 1 da Amazônia; 1 de Pará, 2 do Ceará, e 1 de Amapá. Com relação ao tempo de realização do transplante, obtivemos os sequintes dados: 2 participantes estão transplantados há 6 meses; 3 transpantados há 8 meses; 3 transplantados há 1 ano 6 meses e 1 participante encontra-se transplantado há 2 anos.

Quando buscamos observar a renda dos entrevistados identificamos que oito possuem renda familiar de 1 a 3 salários mínimos, proveniente predominante dos valores recebidos por benefícios assistências e previdenciários, apenas um entrevistado relatou renda de 4 a 5 salários mínimos. Essa disparidade na renda reflete diretamente na alimentação, moradia, lazer, entre tantos outros aspectos da vida. 
Com relação à moradia, seis entrevistados residem em casa própria, de alvenaria; dois em moradia alugada, de alvenaria; e um em moradia própria, de palafita. Ainda com relação a habitação, oito têm acesso a água encanada e saneamento básico, e um revelou não possuir essa mesma infraestrutura. Esses dados são importantes se considerarmos as condições de habitabilidade como um aspecto fundamental durante o transplante.

Quanto ao nível de escolaridade, identificamos que dentre os participantes desta pesquisa 5 possuem ensino médio completo; 2 possuem ensino fundamental; 1 ensino superior; e 1 não é alfabetizado, o que também confirma os dados mais recentes relacionados à escolarização e emprego. Em 2016, para grande parte das atividades a escolaridade dos trabalhadores estava concentrada na categoria do ensino médio completo e superior incompleto (IBGE,2017).

Os entrevistados realizavam atividades laborais diversas, antes do diagnóstico da doença, mantendo-se inativos após o diagnóstico, durante o tratamento dialítico. Assim, foram entrevistados: 1 vendedor; 1 agricultor; 1 microempreendedor; 1 advogado e 5 autônomos.

Verifica-se que cinco entrevistados exerciam atividades laborais de forma autônoma, por falta de emprego formal, realizando atividades predominantemente no setor de serviços, com ocupações como: mecânico e vendedor, sem vínculo ao Regime Geral de Previdência Social, o que confirma os dados da PNAD (2015) que demonstra a predominância da informalidade no mercado de trabalho nas Regiões Norte e Nordeste, que se traduz em elevado contingente de trabalhadores sem acesso aos mecanismos de proteção social relacionados à formalização, deixando-os, portanto, mais vulneráveis a situações adversas como, por exemplo, a doenças e à desocupação. Da mesma forma, inibe o acesso dos mesmos a direitos básicos como a remuneração pelo salário mínimo, além de dificultar o acesso à aposentadoria.

Esse contexto social é o que os sujeitos apresentam em comum, além do diagnóstico de Insuficiência Renal Crônica (IRC) com indicação de transplante. A pessoa com prognóstico de transplante, e que tem acesso à intervenção, na sua maioria precisa se deslocar do seu território de origem para os centros urbanos onde se realizam esse procedimento. No entanto, as dificuldades se iniciam antes de definido o diagnóstico, ou seja, na precariedade do atendimento na atenção básica, tais como: dificuldade de realização de exames em tempo hábil, e falta de integração dos serviços, agravando a situação da doença. Outra dificuldade é o acesso ao Tratamento Fora do Domicílio (TFD)2

\footnotetext{
${ }^{2}$ Programa do Ministério da Saúde que determina que os Estados (e municípios) que não dispõem de serviços de saúde que o usuário necessita, disponibilize uma ajuda de custo para a realização do tratamento fora do seu domicílio. O benefício é para o custeio de transporte, alimentação e hospedagem, do usuário e acompanhante (quando indicada essa necessidade pelo médico). Barbarói, Santa Cruz do Sul, n. 56, p.<189-207>, jan./jun. 2020
} 
Apesar das dificuldades, os sujeitos reconhecem que houve mudanças significativas em suas vidas após o transplante renal, principalmente, em relação aos sintomas advindos do tratamento dialítico ao qual foram submetidos antes do transplante. A hemodiálise é um procedimento por meio do qual uma máquina limpa e filtra o sangue, ou seja, faz parte do trabalho que o rim doente não pode fazer (Sociedade Brasileira de Nefrologia, 2019). Desse modo, para eles o transplante representou maior autonomia, liberdade e autocuidado diante do diagnóstico de IRC.

A minha vida antes do transplante era uma prisão, era três dias fazendo hemodiálise e três dias em casa, eu fiquei em coma duas vezes, me desculpa é que eu fico meio assim, muito emocionado (Entrevistado 4).

Com certeza, não tenho nem dúvidas, é como se você renascesse, a respiração, algumas crises alérgicas diminuíram, condicionamento físico, cor da pele e seguindo à risca as recomendações, aí é que melhora mesmo, você percebe a coisa muito nítida (Entrevistado 2).

No começo eu não aceitava, não queria ir para a hemodiálise, pensava que era o fim do mundo, mas depois tive que aceitar (Entrevistado 6).

Ao relatarem suas limitações durante o período da hemodiálise, alguns participantes enfatizaram, além dos aspectos biológicos trazidos pela terapêutica outras condições relacionadas ao apoio psicossocial. Para eles o distanciamento da rede sociofamiliar foi um fator que comprometeu a adaptação ao procedimento e a espera pelo transplante. Desse modo, identificamos que o suporte sociofamiliar exerce um papel fundamental para o enfrentamento da doença durante todas as fases do transplante, o fortalecimento da rede de apoio sociofamiliar auxilia na adaptação à nova realidade, favorecendo a adesão ao tratamento e refletindo na qualidade de vida do paciente.

Dificuldade que eu tive é que eu fiquei dois anos longe da família né, como eu fiquei bastante tempo aqui aí eu sentia muita falta. Eu fiquei até mais sensível, emocionado, por causa do resultado que o médico deu hoje que eu vou poder voltar pra casa, graças a Deus (Entrevistado 4).

Quanto à situação ocupacional, conforme relato dos entrevistados abaixo, as principais dificuldades na fase pré-transplante foram a conciliação das funções laborativas com a descoberta do diagnóstico, inserção no tratamento dialítico, com a rotina de exames e consultas e em alguns casos a mudança de Estado.

Fazia hemodiálise que me limitava muito, porque eu era uma paciente que sempre sentia muita dor de cabeça, então nos dias de hemodiálise eu não conseguia fazer nada (Entrevistada 3).

Agendar assim os planos de vida, porque, assim, muda tudo, conciliar os horários, as

Em caso de morte do usuário durante o tratamento, o Programa prevê o custeio do traslado do corpo e passagem do acompanhante para o seu domicílio de origem.

Barbarói, Santa Cruz do Sul, n. 56, p.<189-207>,jan./jun. 2020 
audiências, porque além disso, eu ocupei muitos cargos públicos durante minha vida, fui diretor de teatro (7 anos), fui secretario de cultura duas gestões, fui conselheiro de cultura do estado durante 6 anos, aí mudou tudo, deu uma reviravolta (Entrevistado 2).

Eu senti dificuldade em relação aos exames porque demora muito( Entrevistada 3).

Eu senti dificuldade na mudança para Fortaleza, porque o custo de vida aqui é muito alto.A distância da família né, porque a família veio depois, eu tenho duas filhas ( Entrevistado 5).

\section{2. A situação do transplantado no mercado de trabalho}

Um dos objetivos do transplante é proporcionar ao paciente com IRC o retorno às atividades cotidianas, incluindo o trabalho. Com relação ao vínculo trabalhista, cinco participantes são vinculados ao RGPS, desse total, quatro encontram-se de auxílio-doença e um paciente recorreu a aposentadoria por tempo de serviço, logo depois da realização do transplante. Os outros participantes são assistidos pelo Benefício Prestação Continuada (BPC) ${ }^{3}$.

Não obstante, os participantes deste estudo possuem uma particularidade quanto a manter-se trabalhando pós-transplante. Entre os nove entrevistados, apenas três relataram retorno gradativo às atividades. Vale ressaltar que dos três casos apenas um participante retornou à mesma atividade laboral,conforme relato abaixo:

Eu gosto de trabalhar com vendas. Antes do transplante, da hemodiálise, eu vendia cosméticos e maquiagens eu vendia bem, só que quando comecei a fazer hemodiálise não deu pra conciliar os horários da clínica com as reuniões do trabalho, aí eu fiquei muito desmotivada e parei de vender. Voltei agora, depois do transplante. Outro motivo de ter voltado a trabalhar é a questão da renda , que o salário-mínimo é muito pouco, pra complementar na família, porque a gente mora de aluguel, sabe (Entrevistada 3).

Com base no discurso da entrevistada 3, podemos destacar que alguns fatores têm contribuído para o retorno gradativo ao trabalho, o fator principal está relacionado a questão de renda familiar, uma vez que, os valores atribuídos em benefícios como BPC não são suficientes para arcar com as despesas familiares. Além da complementação da renda familiar, para essa entrevistada, o que possibilitou o retorno à mesma atividade profissional foi a adaptação às condições de trabalho, consideradas por ela, como flexíveis à rotina de um transplantado renal.

Como trabalho com vendas online isso me ajuda muito, porque eu fico aqui aguardando uma consulta, tô postando um produto, fazendo uma venda, ligando pro motoqueiro pra ele fazer uma entrega. Para minha irmã que me ajuda a pegar as mercadorias, não tem horário formal, tudo isso me ajuda, porque tem essa flexibilidade (Entrevistada 3).

\footnotetext{
${ }^{3}$ O Benefício de Prestação Continuada (BPC- Idoso/BPC-Deficiente, da Política de Assistência Social, prevista na Lei Orgânica da Assistência Social - LOAS). É um benefício de renda no valor de um salário mínimo, para idosos com 65 anos ou mais de idade, e pessoas com deficiência de qualquer idade, que apresentam impedimentos de longo prazo, de natureza física, mental, intelectual ou sensorial e que, por isso, apresentam dificuldades para a participação e interação plena na sociedade. Para a concessão deste benefício, é exigido que a renda per capita mensal seja inferior a $1 \frac{1}{4}$ de salário mínimo.
}

Barbarói, Santa Cruz do Sul, n. 56, p.<189-207>, jan./jun. 2020 
Vale considerar, ainda, o suporte familiar no processo de retorno do paciente às atividades produtivas após o transplante como um fator que influenciou de forma significativa nesse processo. Não obstante, tais aspectos têm oportunizado um retorno ao trabalho sem grandes impactos no quadro clinico dos pacientes transplantados e tem contribuído na sua autonomia e na sua qualidade de vida.

Os entrevistados 2 e 8 referem que retornaram ao trabalho após o transplante, mas com mudança nas atividades exercidas, e que essa mudança foi necessária devido ao impacto causado pela atividade profissional na sua condição de saúde.

\footnotetext{
Advocacia é uma coisa muito estressante, não deixa de ser né, as vezes eu fico com medo de voltar, como eu tinha uma pressão arterial muito agressiva, eu tive que tomar todo um cuidado em relação a isso, em ter uma vida tranquila, calma. Então eu comecei a fazer produção, a gente tem uma produtora de eventos culturais, eu e minha família, a gente está à frente disso, agora depois do transplante me dedico mais a isso, agora já muda tudo porque já tenho mais tempo mais qualidade de vida, isso seguindo todas as recomendações, sempre fui muito disciplinado (Entrevistado 2).

Quando eu tinha saúde eu trabalhava com produção de eventos, era produtor; hoje nessa função não tem como, porque trabalhava mais a noite, tudo isso tem uma limitação, aí não penso muito em voltar, penso mais em continuar nessa nova área (fabricando linguiças caseiras) fazer cursos me aperfeiçoar sabe, mas tomando cuidado (Entrevistada 8).
}

Para os outros seis participantes (um aposentado, dois em auxílio-doença e três autônomos em BPC), os fatores que têm impossibilitado o retorno ao trabalho, após a realização do transplante, são a falta de oportunidades no mercado e principalmente as limitações impostas pela sua condição de saúde. Àqueles em auxílio-doença, ressaltam, sobretudo, a falta de compreensão por parte dos empregadores, tendo em vista as suas fragilidades, conforme enfatizado pelo entrevistado 6 :

Já penso em trabalhar pra mim, vender alguma coisa em casa, porque hoje em dia patrão geralmente não assina sua carteira se você não tiver lá, porque você tem que vim pra consultas aqui em Fortaleza, às vezes passa 2 a 3 dias; patrão nenhum aceita (Entrevistado 6).

Nesse contexto, outro fator relacionado ao não retorno ao trabalho pós-transplante diz respeito às incertezas dos pacientes em manter-se ou não vinculado a algum benefício assistencial ou previdenciário. No relato da entrevistada 7, observa-se a preocupação com o desemprego e com a possibilidade de cancelamento do seu benefício assistencial caso não consiga readaptar-se ao "novo" trabalho.

Geralmente algumas empresas não aceitam, porque eu tenho que vim pra cá todos os meses né, e tem empresas que não liberam [...]. Porque é direito meu vir mas a pessoa pode não aceitar. Hoje em dia para entender uma situação dessa é difícil. Qualquer coisa se eu arranjar um emprego com carteira assinada eu perco meu benefício, aí se eu perder o emprego, perco todo os dois, aí fica muito complicado (Entrevistada 7).

Pessoas com diagnósticos de IRC em hemodiálise, e em fila de transplante, podem ter Barbarói, Santa Cruz do Sul, n. 56, p.<189-207>, jan./jun. 2020 
acesso ao BPC. Alguns transplantados, dependendo do quadro clínico e das condições de trabalho, podem retornar às atividades laborais e o benefício é suspenso. Ao refletir sobre o processo de retorno ao trabalho com os participantes dessa pesquisa, o que se observou foi uma carência de programas de reabilitação profissional, tanto para aqueles assistidos pelo BPC como pelo auxílio- doença.

Conforme o artigo 89 da Lei $n^{\circ}$ 8213/1991, e artigo 136 do Decreto $n^{\circ} 3.048 / 1999$ do Instituto Nacional do Seguro Social (INSS), a Reabilitação Profissional é a assistência educativa ou reeducativa e de adaptação ou readaptação profissional, denominada genericamente de habilitação e reabilitação profissional (RP), voltada para beneficiários incapacitados parcial ou total para o trabalho, e às pessoas com deficiência. A Reabilitação profissional é de caráter obrigatório e sem carência; e visa proporcionar os meios indicados para o reingresso no mercado de trabalho e no contexto em que vivem. Entretanto, essa assistência contempla apenas os segurados da Previdência Social.

O discurso do entrevistado 2 revela a contraditoriedade entre o texto da lei e a operacionalização do serviço de Reabilitação, pois infere que o serviço ou não é ofertado, ou não é eficaz para proporcionar o retorno às atividades laborais.

Eu fico num certo dilema, porque tô de auxílio-doença há bastante tempo, tenho uma dúvida cruel, não sei se me aposento ou se volto. A pessoa fica numa crise existencial, sabe, porque fica na dúvida se volta, se toma outro rumo, a gente também não tem um acompanhamento para retornar, sabe (Entrevistado 2).

Como podemos observar no quadro abaixo, mesmo com o retorno gradativo às atividades laborais os pacientes mantêm vínculo com algum benefício previdenciário ou assistencial; isso reflete a fragilidade das políticas intersetoriais e o processo de reabilitação que não se consolida de forma eficaz.

A situação do transplantado no mercado de trabalho

\begin{tabular}{|lc|}
\hline Variável & $\mathbf{N}$ \\
\hline Aposentado & 1 \\
Afastado por motivo de doença/ exercendo atividade trabalhista & 2 \\
Afastado por motivo de doença & 2 \\
Afastado por motivo de doença BPC / exercendo atividade trabalhista & 1 \\
Afastado por motivo de doença BPC & 3 \\
\hline
\end{tabular}

Fonte: Elaboração própria, 2019.

Como já visto, o transplante tem como objetivo melhorar a qualidade de vida dos pacientes tornando-os aptos às atividades normais de vida e de trabalho. Contudo, para que isso 
ocorra, é necessária uma abordagem das equipes de saúde, no sentido de apreender melhor as questões que envolvem o trabalho e suas determinações na vida dos pacientes.

A doutora falou que nesses 6 meses eu não posso pegar sol nem peso, foi a recomendação dela, mas se fosse pra trabalhar já dava, assim, em alguma coisa, não em coisas pesadas, porque eu também tenho problema de coluna, não posso carregar muito peso (Entrevistado 1).

Gostaria de arrumar um emprego ou trabalhar pra mim mesmo, sabe, por enquanto não. Amanhã vou pra doutora, vou ver o que ela vai dizer pra mim (Entrevistado 6).

Os depoimentos dos entrevistados 1 e 6 enfatizam a questão das recomendações para o período pós transplante repassadas pela equipe de saúde, ao mesmo tempo evidencia-se que as condições para o retorno ao trabalho dos pacientes podem ser melhor exploradas no serviço como uma forma de avaliar o impacto do transplante na vida desses sujeitos e fomentar um trabalho multidisciplinar.

Em relação ao retorno ao trabalho, a pesquisa revela que $33 \%$ dos entrevistados, que corresponde a 3 pessoas, retornaram ao trabalho. Dentre os que não retornaram ao trabalho, apenas 1 era aposentado. Porém, nenhum deles conseguiu alterar a condição de beneficiário de auxílio-doença ou BPC, mantendo vínculos no mercado de trabalho informal e por conta própria. Esse dado reforça a necessidade de considerar as condições para retorno ao trabalho após tratamento de saúde, como indicadores em estudos sobre as iniquidades em saúde da população.

No contexto atual são muitas as contradições que perpassam a dimensão política, econômica e ética próprias do modelo de organização social capitalista que tem contribuído para agudizar as expressões da questão social. Mendes e Wünsch (2009) ressaltam que as mudanças que envolvem a esfera do trabalho na sociedade atual têm repercussões na proteção social, que estão relacionadas também com as mudanças no papel do Estado.

Dentre as alterações mais recentes definidas pelo Estado podemos citar a Reforma Trabalhista, regulamentada pela Lei 13.467 de 2017, que estabelece dentre outras questões: a ampliação da contratação via terceirização, permitindo também terceirização das atividadesfim, aquelas que configuram efetivamente o principal objetivo da organização, e o trabalho remunerado por hora trabalhada. Outra mudança efetuada no âmbito do Estado que ainda se encontra em curso é a proposta da Reforma Previdenciária, trazida pela Emenda Constitucional $n^{\circ} 103$ que entre outros pontos estabelece novos critérios para aposentadoria.

Diante disso, podemos considerar que as transformações que estão sendo realizadas no campo do trabalho repercutem nas condições de vida e saúde dos trabalhadores, interferindo na suas características de direito social e determinante de saúde. Nessa perspectiva, faz-se 
necessário compreender o retorno dos pacientes ao trabalho, numa maior dimensão, considerando para além das determinações biológicas, incluindo as conexões com o processo socio-histórico no qual estão inseridos.

\section{Considerações finais}

No Brasil, a partir da década de 1990, a reestruturação produtiva introduziu novos processos de trabalho, em que a produção em massa foi substituída por novas formas de adequação da produção à lógica do mercado, alterando a gestão e organização do trabalho. Com essa reconfiguração do trabalho, sob paradigmas neoliberais, ocorre desregulamentação das relações de trabalho, maior precarização e desmonte de direitos sociais e trabalhistas - o que pressupõe, conforme Mendes e Wünsch (2009, p.242) "a intensificação do trabalho, o mercado globalizado e a expropriação dos direitos que resultam em instabilidade, incertezas e inseguranças para os trabalhadores". Antunes (2009) destaca que o mais brutal resultado dessas transformações é a expansão do desemprego que atinge, sobretudo, a população mais jovem.

Desse modo, percebemos que, o que pode interferir na eficácia do tratamento de um transplantado renal, são os fatores que envolvem o retorno ao trabalho, sendo estes: a ineficácia do serviço de reabilitação; o desejo de manter garantido o auxílio doença ou BPC; o desemprego; a instabilidade ou limitações advindas do transplante ou de outras comorbidades; e a forma de acompanhamento após o transplante, que não considera as capacidades laborais de cada paciente.

Compreendemos que a submissão ao transplante renal traz impactos positivos para os que aderem ao tratamento, sobretudo em relação à melhoria da qualidade de vida, e na autonomia das atividades da vida diária. Não obstante, em relação à realização de atividades laborais o que se observa é que de um modo geral é difícil o retorno ao trabalho, mantendo-se a dependência de benefícios da seguridade social, e os que conseguem algum retorno ao trabalho, o conseguem de forma gradativa, informal e sem suporte de outras políticas sociais, principalmente as relacionadas a reabilitação profissional.

Essa realidade aponta para a necessidade do fortalecimento do acompanhamento multiprofissional, com ênfase não só nas condições clínicas, mas levando em consideração os aspectos sociais, entendidos como complementares no cuidado integral a saúde. Faz-se necessário uma melhor interlocução da política de saúde, com outras políticas, tais como: assistência e previdência social, para que sejam consolidados os princípios do SUS da integralidade da atenção e universalidade do acesso a saúde, promovendo intervenções centradas no usuário, visando a autonomia desses sujeitos, buscando estratégias que Barbarói, Santa Cruz do Sul, n. 56, p.<189-207>,jan./jun. 2020 
possibilitem a reinserção ao mercado de trabalho.

Nessa perspectiva a presente pesquisa pretende contribuir para dar visibilidade a temática e assim fomentar o debate junto a sociedade civil e academia que possibilite a construção de espaços para reinserção dos transplantados renais às suas atividades profissionais.

\title{
BETWEEN UNCERTAINTIES AND LIMITATIONS: AN ANALYSIS ON THE RETURN TO WORK AFTER KIDNEY TRANSPLANTATION
}

\begin{abstract}
The present study has the general objective of analyzing the return to work of kidney transplant patients monitored at the Walter Cantídio University Hospital (WCUH). The research has as specific objectives: 1) to identify the factors that influence the return to work process; 2) to identify the rate of reintegration to work by kidney transplant patients seen at the WCUH from June/2018 to December/2018. It is a qualitative research that, according to Minayo (2011), works with a universe of meanings, motivations, aspirations, beliefs, values and attitudes, which corresponds to a deeper space of the relationships of processes and phenomena that cannot be translated into numbers and quantitative indicators. In the methodological structuring of the study, we carried out bibliographic research, documentary research and field research, using, for data analysis, content analysis, considered as the type of methodology particularly used to study qualitative material, thus enabling a critical study of the collected data, of the social representations of the interviewed subjects, establishing, in turn, a dialogue with the studied phenomenon. We understand that submission to kidney transplantation has positive impacts for those who adhere to treatment, especially in relation to improving the quality of life, and in the autonomy of activities of daily living.Nevertheless, in relation to the performance of work activities, what is observed is that, in general, it is difficult to return to work, keeping the dependence on social security benefits, and those who achieve some return to work, do so quickly. gradually, informally and without support from other social policies, mainly those related to professional rehabilitation.
\end{abstract}

Keywords: Return to Work. Unified Health System. Kidney Transplantation.

\section{ENTRE INCERTIDUMBRES Y LIMITACIONES: ANÁLISIS SOBRE EL REGRESO AL TRABAJO DESPUÉS DEL TRASPLANTE DE RIÑÓN}

\section{Resumen}

El presente estudio tiene el objetivo general de analizar el retorno al trabajo de los pacientes con trasplante renal controlados en el Hospital Universitario Walter Cantídio (HUWC). La investigación tiene como objetivos específicos: 1) identificar los factores que influyen en el proceso de retorno al trabajo; 2) identificar la tasa de reintegración al trabajo de los pacientes con trasplante de riñón atendidos en el HUWC desde junio / 2018 hasta diciembre / 2018. Es una investigación cualitativa que, según Minayo (2011), trabaja con un universo de significados, motivaciones, aspiraciones, creencias, valores y actitudes, que corresponde a un espacio más profundo de las relaciones de procesos y fenómenos que no pueden traducirse en números e indicadores cuantitativos. En la estructuración metodológica del estudio, llevamos a cabo investigación bibliográfica, investigación documental e investigación de campo, utilizando, para el análisis de datos, el análisis de contenido, considerado como el tipo de metodología particularmente utilizada para estudiar material cualitativo, permitiendo así un 
estudio crítico. de los datos recopilados, de las representaciones sociales de los sujetos entrevistados, estableciendo, a su vez, un diálogo con el fenómeno estudiado. Entendemos que la sumisión al trasplante de riñón tiene impactos positivos para aquellos que se adhieren al tratamiento, especialmente en relación con la mejora de la calidad de vida y en la autonomía de las actividades de la vida diaria. Sin embargo, en relación con el desempeño de las actividades laborales, lo que se observa es que, en general, es difícil regresar al trabajo, manteniendo la dependencia de los beneficios de la seguridad social, y aquellos que logran cierto retorno al trabajo, lo hacen rápidamente. gradual, informal y sin el apoyo de otras políticas sociales, principalmente las relacionadas con la rehabilitación profesional.

Palabras clave: Regreso al trabajo. Sistema Unificado de Salud. Trasplante de Riñón.

\section{REFERÊNCIAS}

ANTUNES, Ricardo. Adeus ao trabalho? Ensaio sobre as metamorfoses e a centralidade do mundo do trabalho. São Paulo: Cortez, 1995.

ANTUNES, Ricardo. Os sentidos do trabalho : ensaio sobre a afirmação e negação do trabalho. São Paulo, Boitempo, 2009.

ASSOCIAÇÃO BRASILEIRA DE TRANSPLANTE DE ÓRGÃOS. Dados Numéricos da doação de órgãos e transplantes realizados por estado e instituição no período: janeiro / setembro - 2019. Disponível em:〈http://www.abto.org.br/abtov03/Upload/file/RBT/2019/RBT- 2019-jan-set-leitura.pdf> Acesso em: 25 nov. 2019.

ASSOCIAÇÃO BRASILEIRA DE TRANSPLANTE DE ÓRGÃOS. Manual de Transplante Renal, período pós- transplante, 2019. Disponível em:<http://www.abto.org.br/abtov03/Upload/file/manual_transplante_pos.pdf $>$ Acesso em: 25 nov. 2019.

BARATA, Rita Barradas. Como e por que as desigualdades sociais fazem mal a saúde. Coleção Temas em Saúde. Rio de janeiro: Fiocruz, 2009.

BARDIN, Laurence. Análise de Conteúdo. 4. ed. Lisboa: Edições 70, 2010.

BRASIL. Lei $\mathbf{n}^{\mathbf{0}}$ 8.080, de 19 de setembro de 1990. Dispõe sobre as condições para a promoção, proteção e recuperação da saúde, a organização e o funcionamento dos serviços correspondentes e dá outras providências. Brasília: Senado Federal, 1990. Disponível em:< http://www.planalto.gov.br/ccivil_03/leis/L8080.htm >. Acesso em: 13 jun. 2019.

BRASIL. Ministério da Saúde. Política Nacional de Atenção aos Portadores de Doença Renal. Portaria $\mathrm{n}^{\mathrm{o}} 1.168$ de 15 de junho de 2004.

BRASIL. Ministério da Saúde. Secretaria de Assistência à Saúde. Programa de Tratamento Fora de Domicílio. Portaria n ${ }^{\circ} 055$ de 24 de fevereiro de 1999.

BUSS, P. M.; PELLEGRINI FILHO, A. Determinantes Sociais de Saúde. In PHISYS: Revista Saúde Coletiva, Rio de Janeiro, 17 (1) 77-93, 2007.

GIL, Antônio Carlos. Métodos e Técnicas de Pesquisa Social. 5.ed.São Paulo: Atlas, 1999. 
INSTITUTO BRASILEIRO DE GEOGRAFIA E ESTATICA. Síntese de indicadores sociais: uma análise das condições de vida da população brasileira: IBGE, 2018. Disponível em:< https://biblioteca.ibge.gov.br/visualizacao/livros/liv101629.pdf> Acesso em: 26 nov. 2019.

INSTITUTO BRASILEIRO DE GEOGRAFIA E ESTATICA. Pesquisa Nacional por Amostra de Domicílio: IBGE, 2015. Disponível em: < https://biblioteca.ibge.gov.br/visualizacao/livros/liv98887.pdf> Acesso em: 26 nov. 2019.

INSTITUTO NACIONAL DO SEGURO SOCIAL. Reabilitação Profissional. Disponível em:< https://www.inss.gov.br/orientacoes/reabilitacao-profissional/>Acesso em: 25 nov. 2019.

MENDES, R. M. J.; WUNSCH, R. P. O Trabalho no Contexto da Reestruturação Produtiva: determinações históricas e a relação com a saúde. Revista Textos \& Contextos, Porto Alegre, v. 14, n. 2, p. 291 - 302, ago. /dez. 2015.

MENDES, R. M. J.; WUNSCH, R. P. Trabalho, classe operária e proteção social: reflexões e inquietações. Rev. Katál. Florianópolis v. 12 n. 2 p. 241-248 jul./dez. 2009.

MINAYO, Maria Cecília de Souza. Pesquisa Social: teoria, método e criatividade. Editora Vozes: Limitada,2011.

MINISTÉRIO DA SAÚDE. Blog da Saúde. 57,4 milhões de brasileiros têm pelo menos uma doença crônica.2019. Disponível em: $<$ http://www.blog.saude.gov.br/index.php/3486157-4- milhoes-de-brasileiros-tem-pelo-menos-uma-doenca-cronica >. Acesso em: 25 nov. 2019.

ORGANIZAÇÃO MUNDIAL DA SAÚDE. Diminuindo diferenças: a prática das políticas sobre determinantes sociais da saúde, documento de discussão da conferência mundial sobre Determinantes sociais da saúde. Rio de Janeiro, 2011.

SECRETARIA DE SAÚDE DO ESTADO DO CEARÁ. Notícias. Ceará tem segundo melhor resultado em transplantes de órgãos resultado em transplantes de órgão tecidos.2019.Disponivel: <https://www.saude.ce.gov.br/2019/01/29/ceara-tem- segundo-melhorresultado-em-transplantes-de-orgaos-e-tecidos/> Acesso em: 25 nov.2019.

UNIVERSIDADE FEDERAL DO CEARÁ. Hospital Universitário Walter Cantídio HUWC. . Histórico do Hospital Universitário Walter Cantídio. Disponível em:<http://www2.ebserh.gov.br/web/huwc-ufc/nossa-história >Acesso em: 25 nov. 2019.

Data de recebimento: $26 / 02 / 2020$

Data de aceite: 01/06/2020

Sobre as autoras:

Jéssica Rayane dos Santos é Assistente Social. Graduada em Serviço Social pela Universidade Estadual do Ceará (UECE) Especialista em Atenção Hospitalar à Saúde: Área de concentração em Transplante pela Universidade Federal do Ceará- UFC. Especialista em Saúde da Família Barbarói, Santa Cruz do Sul, n. 56, p.<189-207>,jan./jun. 2020 
pela Universidade da Integração Internacional da Lusofonia Afro-Brasileira (UNILAB). Endereço Eletrônico: jrayane93@gmail.com

Maria das Graças Fonseca Rocha é Assistente Social do Hospital Universitário Walter Cantídio (HUWC), Fortaleza/CE. Mestre em Avaliação de Políticas Públicas pela Universidade Federal do Ceará (UFC). Especialização em Administração e Planejamento de Projetos Sociais, pela Universidade Gama Filho(2007); Especialização em Planejamento e Gestão do Sistema Único de Assistência Social, pela Universidade Estadual do Ceará (2011); Especialização em Cuidados Paliativos e Bioética, pela Universidade de Fortaleza (2018).Endereço Eletrônico: rochagraca@hotmail.com.

Maria de Fátima Sousa Lima de Carvalho é Assistente social e psicóloga; especialista em Recursos Humanos pela Universidade Federal do Ceará. Assistente social no Hospital Universitário Walter Cantídio (HUWC- UFC). Endereço Eletrônico: fatimavarelaas@gmail.com. 